\title{
Analysis of Research Progress on Ecological Efficiency Based on Histcite and Web of Science
}

\author{
Longshan Liu ${ }^{1, *}$ Xiaojuan Yuchi ${ }^{2}$ Guangcheng Wang ${ }^{1,3}$
}

\author{
${ }^{1}$ School of Management Science and Engineering, Shandong Technology and Business University, Yantai, Shandong \\ 264005, China \\ ${ }^{2}$ School of Economics, Shandong Technology and Business University, Yantai, Shandong 264005, China \\ ${ }^{3}$ School of Management Science and Engineering, Binzhou Medical University, Yantai, Shandong 264033, China \\ *Corresponding author. Email: $1562182010 @ q q . c o m$
}

\begin{abstract}
In order to understand the evolution of research history and methods of ecological efficiency and provide experience for sustainable development and future ecological efficiency research, HistCite bibliometrics is used as an effective statistics analysis approach. This paper uses "ecological efficiency" as the search term to carry out a subject search, and the search time is January 1, 2020. It analyzes 1024 articles related to ecological efficiency; these articles are collected at the Web of Science database. From 2013 to 2019, the discussion about ecological efficiency revolves around four aspects: core author, annual publication of literature, national publication of the literature, distribution of journals. Finally, according to the cited chronological chart, the critical nodes of ecological efficiency in the area, industry and other aspects are analyzed. The application fields of ecological efficiency are expanding, from countries and regions, manufacturing industry, energy to agriculture, ports, supply chain etc. Based on the traditional Data Envelopment Analysis (DEA) method, the measurement methods of ecological efficiency are improving. Combining the life cycle assessment with energy analytical method and developing from the static section data model to the panel data model are greatly enriched the time and space research of ecological efficiency; researchers are paying more attention to the influencing factors and driving forces of ecological efficiency.
\end{abstract}

\section{Keywords: ecological efficiency, citation analysis, Histcite software, Data Envelopment Analysis (DEA)}

\section{INTRODUCTION}

China's current industrial system is diverse and complete, and China's manufacturing is worldrenowned, but at the same time, it puts tremendous pressure on resources and the environment. General Secretary Xi Jinping put forward the overall layout of the "five in one" strategy, in which ecological civilization construction is a vital part of the overall plan. At the same time of rapid economic growth, environmental pressure also brings troubles to the ecosystem and social development. Therefore, in the development process, we must keep our eyes upon reducing the wasting of resources to achieve highquality economic growth and sustainable development. The more prominent problem is the consumption of fossil energy, which leads to global warming, air pollution and other extreme issues, which severely destroy the biosphere cycle and then affect human beings, so there is an urgent need to recognize the sustainable development. Eco-efficiency is an effective analytical tool for achieving sustainable development, which can calculate relative date of economic activities such as ecological resources and environmental production.

Ecological efficiency is equal to part of the added value of products or services first proposed by Schaltegger in 1990. This basic definition lays the foundation for the study of ecological efficiency. After that, the researchers and relevant organizations have discussed and analyzed the connotation of ecological efficiency, but no unified framework has been formed. After years of development, the research field of ecological efficiency has been expanding. It is necessary to sort out the general situation of its research results and clarify the future development direction. Based on the reference to relevant research reviews [1], [2], [3], combined with Histcite literature measurement software, the research progress of ecological efficiency in the past seven years, is summarized. 


\section{DATA SOURCES AND RESEARCH METHODS}

\section{A. Data source}

Through the use of Histcite bibliometrics, taking the data of Web of Science database as the research object, the retrieval subject term is set as "ecological efficiency", the period is "all years", the retrieval time is January 1st, 2020, and a total of 1024 references are found, which constitutes the data research structure of the literature review.

\section{B. Research methods}

Histcite as a kind of bibliometric software is developed by Dr Eugene Garfield, which helps to sort out the research content and relieves the pressure on the literature management departments, Histcite software has the advantage of accurately finding the research hotspot, historical evolution, development process and the future trend of a specific discipline from the complex and diverse literature. The foreign literature of ecological efficiency mainly uses Histcite for data visualization analysis. The typical indicators of Histcite are:

GCS (Global Cited score) is the number of global citations, that is, the number of citations of literature in the whole Web of Science database by other documentation;

LCS (local cited score) is the number of local citations, that is, the number of citations of literature in the retrieved references, because the essay in the current database are all related to search terms. It can be considered that these articles are related to the research direction. The higher the LCS value is, the higher the importance it has in this research field;

LCR (local cited references) refers to the number of local references, the number of other literature in the relevant references of this discipline have been retrieved by literature references. A certain article references the current situation. The more items in the database, the higher the attention of this research direction, which may represent the new development of this research field, or it may be the review articles in the research field.

$\mathrm{CR}$ (cited references) is the number of references in the whole database of the Web of Science. The higher the value is, the more likely it is to be an overview.

By introducing the data into Histcite software for analysis, the core authors, annual publication of literature, national publication of the literature, distribution of journals and the highly cited in the field of ecological efficiency are sorted and counted, which can help researchers understand the research process of ecological efficiency related issues, as well as the contributions and status of relevant authors, institutions and countries in this field.

\section{RESULT ANALYSIS}

\section{A. Analysis of principal authors}

There are 2889 authors in the field of ecological efficiency from 2013 to 2019 retrieved from the Web of Science, and the top ten authors with the largestest number of local references (TLCS) are selected as shown in "Table I". The authors with the largest number of local references are Munisamy s and Arabi B. They jointly published two articles, see references[15] , [23]. The number of local citations (LCS) of the two papers was 23 and 21, respectively.

From "Table I", the author who has the most considerable amount of papers on ecological efficiency is Emrouznejad a, whose TLCS ranks fourth. The most influential article is published in energy policy in 2014 , with LCS of 23; the next is published in "Omega International Journal of Management Science and LCS" is 11 .

TABLE I. TOP 10 AUTHORS OF ECOLOGICAL EFFICIENCY RESEARCH BY TLCS

\begin{tabular}{|l|l|l|l|l|}
\hline \multicolumn{1}{|c|}{ Author } & TLCS & \multicolumn{1}{c|}{ TGCS } & Number & Percentage \\
\hline Munisamy S & 82 & 168 & 6 & 0.54 \\
\hline Arabi B & 80 & 158 & 6 & 0.54 \\
\hline Egilmez G & 79 & 296 & 9 & 0.80 \\
\hline Emrouznejad A & 68 & 172 & 11 & 0.98 \\
\hline Huang JH & 67 & 112 & 7 & 0.62 \\
\hline Kucukvar M & 62 & 257 & 7 & 0.62 \\
\hline Zhu B & 53 & 169 & 5 & 0.45 \\
\hline Chen DJ & 52 & 155 & 5 & 0.45 \\
\hline Tatari O & 51 & 218 & 5 & 0.45 \\
\hline An QX & 50 & 91 & 3 & 0.27 \\
\hline
\end{tabular}

\section{B. Analysis of publication time}

From 2013 to 2019, literatures published in the field of ecological efficiency shows an increasing trend year by year, as shown in Figure 1. From 2013 to 2019, the number of documents shows a rapid growth trend. In 2018 , the number of records was 229, about 2.5 times that of 2013. (See "Fig. 1")

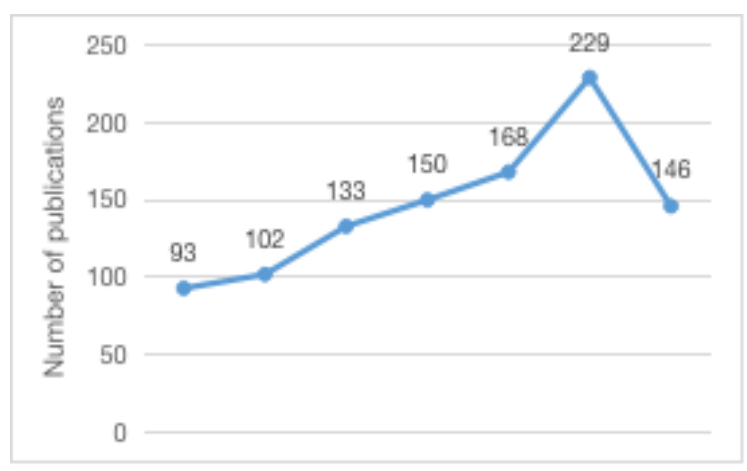

Fig. 1. Annual distribution of literature on ecological efficiency. 


\section{Distributions of published countries}

The top ten countries are China (268), Spain (91), Britain (91), the United States (87), Germany (71), Italy (67), Brazil (64), Australia (58), France (49) and Portugal (40), respectively. The total number of publications in 10 countries is 886 , accounting for $79 \%$ of all pieces of literature. The top 10 states were China (632 times), Britain (169 times), the United States (148 times), France (114 times), Spain (110 times), Malaysia (99 times), Italy (78 times), Austria (69 times), Brazil (66 times) and Germany (65 times). Chinese literature is the first in quantity and TLCS ranking, and has an apparent comparative advantage with the second, and is in a dominant position in the field of ecological efficiency research. Although the number of literature in Malaysia and Austria did not reach the top 10, TLCS ranked sixth and eighth respectively, which indicated that Malaysia and Austria had more in-depth and high influence in the study of ecological efficiency. ("Table II" and "Table III")

TABLE II. TOP 10 COUNTRIES IN TERMS OF ECOLOGICAL EFFICIENCY RESEARCH LITERATURE BY THE QUANTITY

\begin{tabular}{|l|l|l|}
\hline \multicolumn{1}{|c|}{ Country } & Number & Percentage \\
\hline Peoples R China & 268 & 23.91 \\
\hline Spain & 91 & 8.12 \\
\hline UK & 91 & 8.12 \\
\hline USA & 87 & 7.76 \\
\hline Germany & 71 & 6.33 \\
\hline Italy & 67 & 5.98 \\
\hline Brazil & 64 & 5.71 \\
\hline Australia & 58 & 5.17 \\
\hline France & 49 & 4.37 \\
\hline Portugal & 40 & 3.57 \\
\hline
\end{tabular}

TABLE IV. THE NUMBER OF TOP 10 JOURNALS OF TLCS ON ECOLOGICAL EFFICIENCY

\begin{tabular}{|l|l|l|l|l|}
\hline \multicolumn{1}{|c|}{ Journal } & TLCS & Number & Percentage & TGCS \\
\hline Journal of Cleaner Production & 636 & 238 & 21.23 & 4255 \\
\hline Ecological Indicators & 153 & 22 & 1.96 & 458 \\
\hline Energy Policy & 68 & 13 & 1.16 & 177 \\
\hline European Journal of Operational Research & 62 & 13 & 1.16 & 301 \\
\hline Environmental \& Resource Economics & 49 & 6 & 0.54 & 85 \\
\hline Resources Conservation and Recycling & 48 & 21 & 1.87 & 375 \\
\hline Energy Economics & 41 & 7 & 0.62 & 195 \\
\hline Energy & 38 & 14 & 1.25 & 155 \\
\hline Renewable \& Sustainable Energy Reviews & 37 & 11 & 0.98 & 281 \\
\hline Annals of Operations Research & 35 & 11 & 0.98 & 113 \\
\hline
\end{tabular}




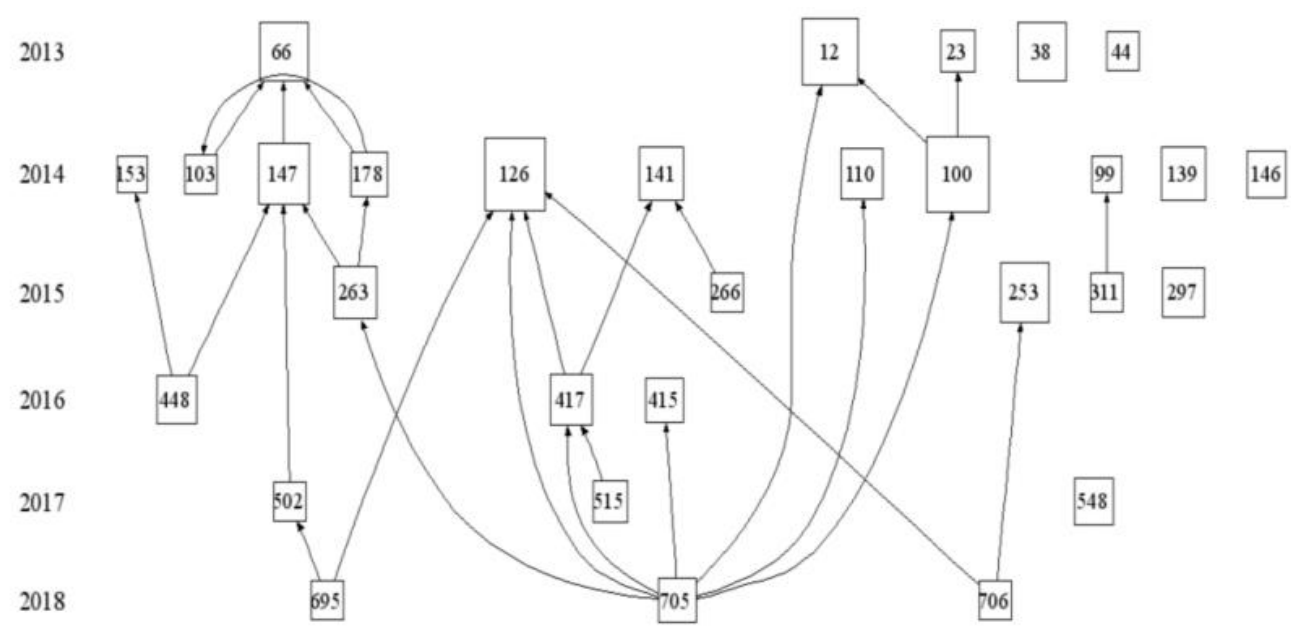

Fig. 2. Citation chronology of ecological efficiency research literatures.

\section{ANALYSIS OF THE EVOLUTION PATH OF ECOLOGICAL EFFICIENCY RESEARCH}

The document citation chronology map is a central function of Histcite. Using the mapping function of Histcite software, the number of nodes of the document is set to 30 based on the current amount of database citations. The evolution path of document researches in the field of ecological efficiency is shown in "Fig. 2". The figure shows the publication time, researching process and mutual relationship of the 30 documents most recognized by scholars in this field. According to the above results, we can explore future research trends in the field of ecological environment. On the left side of the figure is the time of literature publication. The box parallel to the time of literature publication indicates the published literature of the year. The number in the box is the document number. The size of the box shows the number of times that researches have been cited. According to the arrows between the boxes, analyze the citation relationship between the literatures.

In 2013, many of classic literatures appeared, such as literature $12,38,66$, etc., of which literature 12 is the largest node in the literature published in 2013. In literature 12, Yadong Yu et al. Studied the decoupling effect of economic growth and relate environmental destruction in China from 1978 to 2010, calculated the ecological efficiency of China, exploring the reasons for the dynamic change of ecological efficiency, and thought that the overall ecological efficiency was improving. However, the decoupling effect is not obvious from 2001 to 2010. GDP growth is calculated by a variety of consumption of resources, such as the expedition and utilization of mineral resources [4]; In document 23, Alessandro and others evaluate the ecological efficiency of the fruit production system in northern Italy using the multifunctional ecological footprint method. Due to the high output and high market value, less investment is needed, apricot and nectarine have a higher ecological performance. kiwifruit needs more investment, but its market value is low, resulting in low ecological efficiency [5]; in document 38, Mariam et al. Evaluated the ecological efficiency and club convergence of 22 OECD countries during 1980-2008, and found that in addition to the emissions of nitrogen oxides, the ecological efficiency in the whole region showed an upward trend, Scandinavian countries Furniture has high ecological efficiency. The ecological efficiency of southern European countries is generally low. High ecological efficiency countries and low ecological efficiency countries are easy to form club convergence [6]; in document 44, George $\mathrm{E}$ and other countries used the condition oriented distance function to study the ecological efficiency of the UK region and found that with the increase of capital GDP per unit, the ecological efficiency decreased first and then increased. The rising U-shaped trend enriches the research on the decoupling effect of ecological environment and economic development [7]; in document 66, Gokhan and others integrated input-output methods, life cycle assessment and DEA have evaluated the ecological efficiency of the manufacturing sector in the United States. Firstly, the greenhouse gas emissions, energy use, water intake and the generation of harmful substances are quantified through the life cycle model of input-output. Then the input-oriented DEA model is used to score and rank, and finally, the sensitivity analysis is conducted on the influencing factors of ecological efficiency. The results show that the oil and coal industry, food manufacturing industry, printing press related industry and automobile manufacturing industry are ecological efficiency effective, and the use of energy has the highest sensitivity, so the use of renewable resources can significantly improve the ecological efficiency [8];

In 2014, the number of articles with high local citation rate was the most, indicating that the research 
on ecological efficiency reached a small peak in this year. There are 100, 126, 147, and so on. In document 99, Su Song uses the economic environment ratio method to evaluate the ecological efficiency of Shanghai Yangshan port. In terms of environmental impact, it mainly includes the ship's emission impact and social cost. According to the modern automatic identification system, the data of the ship's emission list at the port is obtained, and the relevant social cost is calculated. The economic output includes the number of ships, the number of containers, the port revenue, etc.[9]; in document 100, Yinke et al. Applied ecological efficiency to the study of urban sustainable development, and analyzed the case of provincial capital cities in China. Using DEA model, environmental pollution was regarded as an unexpected output, and the modified super efficiency model was used for ranking. Almost half of the cities were found to be effective in ecological efficiency, while the cities with ineffective ecological efficiency were mainly distributed in the undeveloped areas such as northwest and southwest China, this paper suggests that we should change the GDP oriented growth model and evaluation system, constantly transform and upgrade the industrial structure, and stop the transfer of heavy industry from the southeast coast to the west, and from the city to the countryside [10]; in document 103, Gokhan and others used life cycle evaluation and DEA to analyze the supply chain of food manufacturing industry in the United States. According to the evaluation of sustainable development, it is found that forest ecological footprint is the most sensitive factor affecting the sustainable development of food manufacturing industry [11]; in document 110, hung suck Park and others used the economic environment ratio method to evaluate seven industrial symbiosis networks in Weishan eco-industrial park of South Korea from 2007 to 2012. According to the definition of ecological efficiency by the World Association for sustainable development, ecological efficiency includes one Economic indicator and three environmental indicators, namely raw material consumption, energy consumption and $\mathrm{CO} 2$ emissions, are studied. The results show that the industrial symbiosis network has increased the ecological efficiency by $10 \%$ [12]; in reference 126, Yang Xiaoguang and others have studied the ecological efficiency of China by using the extended DEA model (GB-US-SBM Model), and found that the ecological efficiency has declined first. According to the analysis of the eastern, central, western and northeast regions, the ecological efficiency in the western region has a large space for improvement in technical progress, and all regions in the country can improve the ecological efficiency through the improvement of management ability [13 ]; In document 139, Zhu Zengyin, et al. of Jiangsu Academy of Environmental Sciences, applied network DEA to the evaluation of ecological efficiency of insecticides and compared the ecological efficiency of 10 different insecticides. It was found that compared with singlestage DEA method, network DEA can distinguish the differences of ecological efficiency of products in different stages [14]; in document 141, Behrouz Arabi and other researchers based on relaxation variables. According to Malmquist Luenberger index, the change of ecological efficiency of power industry restructuring is studied. The results show that although industrial restructuring has different effects on ecological efficiency, the rise of ecological efficiency is mainly due to the improvement of technical efficiency [15]; in literature 146, Mikulas luptacik and others based on Leontief input-output model and DEA model to the multi-sector economic system [16]. In reference 147, angel Avadi et al. Evaluated the ecological efficiency of the fishing fleet of anchovy in Peru by using the life cycle assessment method and the DEA framework, and explored the ecological efficiency of the fishing fleet of different sizes [17]; in reference $153, \mathrm{~K}$. thanawong et al. Compared ecological efficiency of the rice production of rainwater irrigation and artificial irrigation in Thailand [18]; in document 178, Gokhan egilmez analyzed the carbon emission, energy consumption and water footprint related to manufacturing transportation in the United States. In various of calculating methods: firstly, by using economic input-output statistics approach and life cycle assessment, the environmental impact of manufacturing and transportation can be reasonable quantification. Then the ecological efficiency was calculated by using the DEA method. The results show that the food manufacturing industry is the main driver of carbon emissions, energy consumption and water footprint. In addition to the tobacco industry, the manufacturing industry in the United States needs to reduce carbon emissions, energy consumption and water footprint by half to reach the ecological efficiency frontier [19].

In 2015, important literature nodes such as 253 , 263, 297, etc. can be found in this period, the Malmquist index and its combination model become a hot research method. In the literature 253, Long Xingle et al., School of Management, Jiangsu University, made a comparative analysis of TFP and ecological efficiency of Chinese cement plants from 2005 to 2010, compared the differences between TFP and ecological efficiency, explored the decisive factors of Malmquist index and Malmquist Luenberger index of Chinese cement manufacturing, and found that the industrial output value of each labor force was consistent with Malmquist index and the Malmquist Luenberger index first decreased and then increased [20]; in reference 263, Kamran and others used DEA model to divide the input into energy input and non energy input, and the output into expected output and non expected output. Some OECD countries were analyzed. The results showed that Australia, Finland, Ireland, New Zealand 
and Switzerland are countries without effective ecological efficiency, while others are countries with effective ecological efficiency. The more energy input is, the more unexpected output is [21]; in document 266, Chungwon et al. Calculated the static and dynamic ecological efficiency of renewable energy in OECD countries based on Malmquist index. The results show that the United States has the highest environmental efficiency, the European countries have the largest standard deviation in ecological efficiency, The global financial crisis has a great impact on the dynamic ecological efficiency [22]; in document 297, Susila Munisamy and others used the common frontier Malmquist Luenberger productivity index to measure the changes in the ecological efficiency of Iran's power plants in the past eight years, making up for the impact of the introduction of new technology by decisionmaking units that the traditional data packet analysis method cannot identify [23]; in document 311, MI Luce tichvska et al. Studied the environmental cost of Las Palmas port and the ecological efficiency of ship exhaust gas [24], and document 311 quoted document 99 , which belongs to the study of port ecological efficiency.

In 2016, there are 415, 417 and 448 are essential nodes. In the field of agriculture, scholars mostly use DEA combined with "life cycle" evaluation method, and DEA panel data model is still the research hotspot. In document 415, Kiyotaka Masuda used DEA and life cycle evaluation model to evaluate the ecological efficiency of wheat production in Japan. Comparing the wheat growing in paddy field with that growing in highland, it was found that no matter in which case, it can reach the production frontier. Reducing the use of nitrogen fertilizer can reduce water eutrophication and improve ecological efficiency [25]; in document 417, $\mathrm{Yu}$ Chang et al. Used Mamlquist Luenberger to calculate the ecological efficiency of China's pulp and paper industry, and found that industrial merger and reorganization improved the scale efficiency, and government supervision could promote enterprises to pay attention to unexpected output, thus reducing the external cost of the environment and improving the ecological efficiency [26]; in document 448, Asmat Ullah et al. Used life Cycle evaluation and DEA to measure the ecological efficiency of the cotton production system in Pakistan. It was found that the level of ecological efficiency had nothing to do with the size of farms, and the use of chemical fertilizers and pesticides reduced the ecological efficiency [27].

In 2017, important nodes such as 502, 515, 548, etc., multi-stage DEA model and cross efficiency DEA model became new research hotspot. In document 502, Liu Xiaohong and others used DEA cross efficiency model to analyze the ecological efficiency of coal-fired power plants, solved the problem that the weight in DEA model is not unique, and can sort decision-making units [28]; in document 515, Zhang Jiangxue and others used Three-stage DEA model to quantify the ecological efficiency of China's inter provincial industries in 20052013. In 2005-2013, the ecological efficiency of 30 provinces increased at different rates, and the level of management, science and technology, and scale economy could improve the industrial ecological efficiency [29]; in document 548, Qiao Qi, Chinese Academy of Environmental Sciences and other scholars used DEA model to study the ecological efficiency of China's Industrial Parks [30]. In 2018, there are 695, 705 and 706 important document nodes. At this stage, the research frontier of ecological efficiency includes common frontier DEA model based on relaxation variables, global DEA method based on bootstrapping, etc. In document 695, Zhang Ning and others integrated ecological efficiency, economic efficiency, energy efficiency and environmental efficiency into a framework of all factor analysis, and used the MetaUS-SBM DEA model to analyze the data of China's provinces from 2001 to 2014. The ecological efficiency indicators with obvious heterogeneity showed that different regions adopted different development models [31]; in document 705, Yang Lin and others used Based on the global DEA analysis method of bootstrapping method, the ecological efficiency of China in 20032014 is calculated. The research revealed that there is a large gap between different regions, technological progress as the decisive factor can promote the ecoefficiency, and the declination of management level became the biggest obstacle of improving ecoefficiency[32]; In document 706, Ren Shenggang and others further explored the administrative order. The research finds that market-based supervision and spontaneous supervision have a positive effect on ecological efficiency in the eastern region, and administrative order based supervision and marketbased supervision have a significant impact on ecological efficiency in the central region. In the western region, administrative order based supervision and market-based supervision have a significant effect on ecological efficiency. Imperative regulation has a significant effect on ecological efficiency [33].

\section{CONCLUSION}

Based on the HistCite bibliometric software, this paper studies 1024 papers in the field of ecological efficiency in the Web of Science database from 2013 to 2019 , summarizes the positive progress in the research of ecological efficiency from the author, publication time, country and Journal, and analyzes the important nodes in the development of ecological efficiency in combination with the citation chronology. With the help of Histcite software, it is more scientific and convenient to summarize the research of ecological efficiency. Through the mutual reference between papers, we can find the research basis and the frontier of the research 
field. In this paper, the research method of ecological efficiency is developed from a single model to multimodel. More elements of resources and environment are integrated into the evaluation of ecological efficiency. From the DEA model based on cross-section data to the Malmquist model based on panel data, the trend of different decision-making units in a period is presented. From the perspective of research, we can judge whether the decision-making unit is effective by simply measuring the ecological efficiency, introduce super-efficiency DEA to rank the efficiency value of the decision-making unit and develop to analyze the influencing factors of ecological efficiency by introducing Tobit and other models. In the field of application, from the different country and region, industrial eco-efficiency evaluation has a more micro and specific industrial park, port, supply chain or other fields. In recent decades, the research on ecological efficiency has achieved fruitful results. According to the number of papers, relative research on ecoefficiency is still in the rising stage. In the future, new progress can be made in the intersection and integration with other disciplines, such as the integration of different industrial symbiosis theory on the ecological efficiency of ecological industrial parks, the research on industrial ecological efficiency under the management disposability, and the spatial calculation. The integration of quantitative economic model can measure the ecological efficiency related to regional spatial distribution structure, and analyze the driving factors of ecological efficiency.

\section{References}

[1] Hu Yina, Peng Jian, Liu YanXu, Wang man, Wang Yanglin. Research progress of regional ecological efficiency. Journal of ecology, 2018, 38 (23): 8277-8284.

[2] $\mathrm{Li} \mathrm{Li}$, Zhang Hua. Overview of DEA based regional environmental performance research. Ecological economy, 2016, 32 (09): 167 - 172.

[3] Sun Yuanyuan, Wu Chunyou. Review of industrial ecological efficiency and evaluation. Science and technology management, 2008 (11): 192-194.

[4] Yu Y, Chen D, Zhu B, et al. ecological efficiency trends in China, 1978-2010: Decoupling environmental pressure from economic growth. Ecological Indicators. 2013, 24: 177-184

[5] Cerutti A K, Beccaro G L, Bagliani M, et al. Multifunctional Ecological Footprint Analysis for assessing ecological efficiency: a case study of fruit production systems in Northern Italy. Journal of Cleaner Production. 2013, 40: 108-117.

[6] Camarero M, Castillo J, Picazo-Tadeo A J, et al. ecological efficiency and Convergence in OECD Countries. Environmental \& Resource Economics. 2013, 55(1): 87-106.

[7] Halkos G E, Tzeremes N G. A conditional directional distance function approach for measuring regional environmental efficiency: Evidence from UK regions. European Journal of Operational Research. 2013, 227(1): 182-189.

[8] Egilmez G, Kucukvar M, Tatari O. Sustainability assessment of U.S. manufacturing sectors: an economic input output-based frontier approach. Journal of Cleaner Production. 2013, 53: 91 102.

[9] Song S. Ship emissions inventory, social cost and ecologica efficiency in Shanghai Yangshan port. Atmospheric Environment. 2014, 82: 288-297.

[10] Yin K, Wang R, An Q, et al. Using ecological efficiency as an indicator for sustainable urban development: A case study of Chinese provincial capital cities. Ecological Indicators. 2014 36: 665-671.

[11] Egilmez G, Kucukvar M, Tatari O, et al. Supply chain sustainability assessment of the US food manufacturing sectors: A life cycle-based frontier approach. Resources Conservation and Recycling. 2014, 82: 8-20.

[12] Park H, Behera S K. Methodological aspects of applying ecological efficiency indicators to industrial symbiosis networks. Journal of Cleaner Production. 2014, 64: 478-485.

[13] Huang J, Yang X, Cheng G, et al. A comprehensive ecological efficiency model and dynamics of regional ecological efficiency in China. Journal of Cleaner Production. 2014, 67: 228-238.

[14] Zhu Z, Wang K, Zhang B. Applying a network DEA model to quantify the ecological efficiency of products: a case study of pesticides. Journal of Cleaner Production. 2014, 69: 67-73.

[15] Arabi B, Munisamy S, Emrouznejad A, et al. Power industry restructuring and ecological efficiency changes: A new slacksbased model in Malmquist-Luenberger Index measurement. Energy Policy. 2014, 68: 132-145.

[16] Mahlberg B, Luptacik M. ecological efficiency and ecoproductivity change over time in a multisectoral economic system. European Journal of Operational Research. 2014 234(3): 885-897.

[17] Lorenzo-Toja Y, Vazquez-Rowe I, Chenel S, et al. ecological efficiency analysis of Spanish WWTPs using the LCA plus DEA method. Water Research. 2015, 68: 651-666.

[18] Thanawong K, Perret S R, Basset-Mens C. ecological efficiency of paddy rice production in Northeastern Thailand: a comparison of rain-fed and irrigated cropping systems. Journal of Cleaner Production. 2014, 73: 204-217

[19] Egilmez G, Park Y S. Transportation related carbon, energy and water footprint analysis of US manufacturing: An ecological efficiency assessment. Transportation Research Part D Transport and Environment. 2014, 32: 143-159.

[20] Long X, Zhao X, Cheng F. The comparison analysis of total factor productivity and ecological efficiency in China's cement manufactures. Energy Policy. 2015, 81: 61-66.

[21] Rashidi K, Saen R F. Measuring ecological efficiency based on green indicators and potentials in energy saving and undesirable output abatement. Energy Economics. 2015, 50: 18-26.

[22] Woo C, Chung Y, Chun D, et al. The static and dynamic environmental efficiency of renewable energy: A Malmquist index analysis of OECD countries. Renewable \& Sustainable Energy Reviews. 2015, 47: 367-376.

[23] Munisamy S, Arabi B. ecological efficiency change in power plants: using a slacks-based measure for the meta-frontier Malmquist-Luenberger productivity index. Journal of Cleaner Production. 2015, 105: 218-232.

[24] Tichavska M, Tovar B. Environmental cost and ecological efficiency from vessel emissions in Las Palmas Port. Transportation Research Part E-Logistics and Transportation Review. 2015, 83: 126-140.

[25] Masuda K. Measuring ecological efficiency of wheat production in Japan: a combined application of life cycle assessment and DEA. Journal of Cleaner Production. 2016, 126: 373-381.

[26] Yu C, Shi L, Wang Y, et al. The ecological efficiency of pulp and paper industry in China: an assessment based on slacks 
based measure and Malmquist-Luenberger index. Journal of Cleaner Production. 2016, 127: 511-521.

[27] Ullah A, Perret S R, Gheewala S H, et al. ecological efficiency of cotton-cropping systems in Pakistan: an integrated approach of life cycle assessment and DEA. Journal of Cleaner Production. 2016, 134(B): 623-632.

[28] Liu X, Chu J, Yin P, et al. DEA cross-efficiency evaluation considering undesirable output and ranking priority: a case study of ecological efficiency analysis of coal-fired power plants. Journal of Cleaner Production. 2017, 142(SI2): 877-885.

[29] Zhang J, Liu Y, Chang Y, et al. Industrial ecological efficiency in China: A provincial quantification using three-stage DEA. Journal of Cleaner Production. 2017, 143: 238-249.

[30] Fan Y, Bai B, Qiao Q, et al. Study on ecological efficiency of industrial parks in China based on DEA. Journal of Environmental Management. 2017, 192: 107-115.

[31] Huang J, Xia J, Yu Y, et al. Composite ecological efficiency indicators for China based on DEA. Ecological Indicators. 2018, 85: 674-697.

[32] Yang L, Zhang X. Assessing regional ecological efficiency from the perspective of resource, environmental and economic performance in China: A bootstrapping approach in global DEA. Journal of Cleaner Production. 2018, 173: 100-111.

[33] Ren S, Li X, Yuan B, et al. The effects of three types of environmental regulation on ecological efficiency: A crossregion analysis in China. Journal of Cleaner Production. 2018, 173: $245-255$. 